\title{
Diversidade genética de espécies de Capsicum com base em dados de isozimas
}

\author{
Tiago Signorini $^{1}$; Erasmo Renesto ${ }^{2}$; Maria de Fátima PS Machado² ; Danielle das N Bespalhok $^{1}$; Eliane R \\ Monteiro ${ }^{1}$ \\ ${ }^{1}$ UEM, Depto. Agronomia, Av. Colombo 5790, 87020-900 Maringá-PR; tiagosignorini22@hotmail.com; dani_bespalhok@hotmail.com; \\ eli.monteirobio@gmail.com; ㄹEM, Depto. Biol. Celular, Av. Colombo 5790,87020-900 Maringá-PR; mfpsmachado@uem.br; ere- \\ nesto@hotmail.com
}

\section{RESUMO}

O gênero Capsicum compreende um rico gênero em aspectos morfológicos e genéticos. Estudos de diversidade genética ligada a este gênero são necessários para maior compreensão sobre as espécies, além de descobertas sobre novas informações em bancos de germoplasma de Capsicum. Este trabalho teve como objetivo analisar a variabilidade genética de três espécies do Capsicum (9 acessos) oriundas do Banco Ativo de Germoplasma da Universidade Federal do Piauí (BAGC). Para isso, utilizou-se da técnica de eletroforese de isoenzimas em gel de amido para a análise de cinco sistemas isoenzimáticos (ACP, GPI, IDH, MDH e PGM). Foram detectados sete loci enzimáticos e 13 alelos, sendo que cinco alelos foram exclusivos, três presentes na população de $C$. annuum var. glabriusculum (Gpi(c), Idh(a) e $A c p(b)$ ) e os demais na população de C. baccatum var. pendulum (Pgm-1(b) e Pgm-2(b)). Todas as populações apresentaram loci polimórficos. O número médio de alelos por locus variou entre 1,4286 e 1. As identidades e as distâncias genéticas de Nei (1972) calculadas demonstraram uma diferenciação entre as espécies. O dendrograma de UPGMA construído demonstrou que as populações foram agrupadas em dois conjuntos: $C$. annuum var. glabriusculum $+C$. chinense e $C$. baccatum var. pendulum. Concluímos portanto, que a diversidade genética dos acessos analisados é baixa e que os métodos utilizados nesta pesquisa são eficazes na diferenciação de espécies de Capsicum, comprovando assim a grande diversidade presente no gênero Capsicum.

Palavras-chave: aloenzima, variabilidade genética.

\begin{abstract}
Genetic diversity of species of Capsicum based on allozymes data

The genus Capsicum comprises richness in morphological and genetic aspects. Studies of genetic diversity about this kind of genus are necessary to a further understanding about species, besides discoveries about new information in Capsicum germplasm banks. This study aimed to analyze the genetic variability of three species of Capsicum (9 accessions) from the Active Germplasm Bank of the Federal University of Piaui (BAGC). We used the technique of isozyme electrophoresis in starch gel for the analysis of five isozyme systems (ACP, GPI, IDH, MDH and PGM). As a result seven enzymatic loci and 13 alleles were detected, considering that, five alleles were exclusive, three were in the $C$. annuum var. glabriusculum (Gpi(c), Idh(a) and Acp (b)) sample, and the others were found in the C. baccatum var. pendulum (Pgm-1(b) and Pgm-2(b)) sample. All samples had polymorphic loci. The average number of alleles per locus varied between 1.4286 and 1. The calculated identities and Nei (1972) genetic distance showed a differentiation among the species. The constructed UPGMA dendrogram showed that the samples were grouped into two sets: $C$. annuum var. glabriusculum $+C$. chinense and $C$. baccatum var. pendulum. Therefore we concluded that the genetic diversity in the analyzed accessions is low and the methods used in this study are effective to differentiate species of Capsicum, proving the great diversity present in the genus Capsicum.
\end{abstract}

Keywords: isozyme, genetic variability.

\section{(Recebido para publicação em 10 de julho de 2012; aceito em 24 de setembro de 2013)} (Received on July 10, 2012; accepted on September 24, 2013)

\begin{abstract}
$\mathrm{A}$ s pimentas são todas as espécies e variedades do gênero Capsicum com frutos geralmente menores que os pimentões, com diferentes formatos, frequentemente de paladar pungente, embora haja pimentas doces. Em alguns casos, elas também são utilizadas como ornamentais, em razão da folhagem variegada, do porte anão e dos frutos com diferentes cores no processo de maturação (Carvalho et al., 2003). O gênero Capsicum pode ser associado à medicina tradicional humana, no combate de
\end{abstract}

enfermidades em criações domésticas. Entretanto, é mais fortemente relacionado a produtos condimentares, devido aos alcalóides (capsaicinóides) contidos em seus frutos. Além disso, as pimentas deste gênero também são excelentes fontes de $\beta$-caroteno, vitaminas $\mathrm{A}$ e $\mathrm{C}$ (Barbosa, et al., 2002).

Do ponto de vista social, o agronegócio de pimenta tem importância, principalmente, em função de requerer grande quantidade de mão-de-obra, em especial durante a colheita. Além disso, o mercado de pimenta abrange a comercialização de frutos para consumo in natura e conservas caseiras até a exportação da páprica, pó de pimentão ou pimenta doce madura vermelha. Os frutos de pimentas picantes podem ser desidratados e comercializados inteiros, em flocos (calabresa) e em pó (páprica picante) ou, ainda, em conservas e em molhos líquidos (Moreira et al., 2006). As pimentas do gênero Capsicum são amplamente cultivadas pelo mundo, sendo utilizadas como matéria-prima 
para as indústrias alimentícia, farmacêutica e cosmética (Bento et al., 2007). A produção vem crescendo muito nos últimos anos, com cultivos em regiões de clima subtropical, como no Sul, ou tropical, como no Norte e Nordeste. Os principais estados produtores são Minas Gerais, Goiás, São Paulo, Ceará e Rio Grande do Sul. O cultivo de Capsicum ocorre praticamente em todas as regiões do Brasil e é um dos melhores exemplos de agricultura familiar e de integração de pequeno agricultor-indústria. Para que seja possível o crescimento deste agronegócio, é fundamental o aumento da produtividade agrícola, mediante o desenvolvimento de cultivares de diferentes tipos de pimenta com resistência a múltiplas doenças e com características agronômicas e industriais de interesse (Ribeiro et al., 2003).

Os frutos das pimentas picantes estão cada vez mais presentes na dieta dos países das regiões tropicais das Américas, da África e da Ásia. As pimentas doces são preferidas por consumidores das regiões temperadas, como a Europa e a América do Norte. C. annuum é provavelmente a mais cultivada das espécies do gênero. Nesta espécie, incluem-se os pimentões e cultivares de pimentas, algumas das quais ornamentais (Pickersgill, 1997).

No mundo, de toda a área cultivada com pimentas, aproximadamente $89 \%$ está no continente Asiático, com as principais áreas de cultivo localizadas na Índia, Coréia, Tailândia, Vietnã, Sri Lanka e Indonésia. Os Estados Unidos e o México respondem por cerca de $7 \%$ do total mundial e por último, $4 \%$ da área cultivada está nos países da Europa, África e Oriente Médio (Rufino \& Penteado, 2006).

$\mathrm{Na}$ Amazônia brasileira, o cultivo de pimentas do gênero Capsicum é uma importante fonte alternativa de geração de divisas para as populações agrícolas da região (indígena e não-indígena), uma vez que o Brasil e, principalmente a Amazônia, é importante centro secundário de espécies domesticadas desse gênero. As pimentas são muito utilizadas, principalmente na alimentação das populações indígenas na "damorida", um caldo à base de água, proteína animal e pimenta (Reifschneider, 2000).
A avaliação da variabilidade genética entre cultivares para fins de conservação de recursos genéticos é útil para saber se dois indivíduos com fenótipos semelhantes exibem uma combinação gênica similar (Lefebvre et al., 2001). Os estudos de distância genética são de grande importância na diferenciação de populações e acessos de bancos de germoplasma, assim como na identificação de genitores adequados à obtenção de híbridos, com maior efeito heterótico e que proporcionem maior segregação em recombinações, possibilitando o aparecimento de transgressivos (Cruz \& Carneiro, 2003).

Os estudos de sistemática e variabilidade genética das pimentas e pimentões têm sido baseados, principalmente, em características morfológicas, cruzamentos interespecíficos e fertilidade dos híbridos interespecíficos (Rêgo, 2001). Diversos métodos para medir distância genética, como descritores fenotípicos e marcadores moleculares, têm sido sugeridos em estudos de diversidade das espécies de pimentas e pimentões (Toquica et al., 2003; Sudré et al., 2005). As técnicas de análises multivariadas têm sido empregadas para quantificação da divergência genotípica e fenotípica em várias espécies de hortaliças (Costa et al., 2006; Sudré et al., 2005). O estudo de divergência permite conhecer o grau de seleção da variabilidade genética das populações vegetais e subsidia a seleção de genitores geneticamente mais divergentes, que poderão ser utilizados em intercruzamentos com possibilidade de aumentar a probabilidade de recuperação de segregantes superiores em gerações avançadas (Cruz \& Carneiro, 2003).

O objetivo deste trabalho foi analisar a variabilidade genética de três espécies do gênero Capsicum, oriundas do Banco Ativo de Germoplasma da Universidade Federal do Piauí por meio da técnica de eletroforese de isoenzimas, para assim propor informações sobre as possíveis diferenças entre as espécies em nível gênico e fornecer subsídios para o melhoramento genético destas espécies.

\section{MATERIAL E MÉTODOS}

As três espécies de Capsicum envol- vidas neste estudo pertencem à coleção do Banco Ativo de Germoplasma de Capsicum (BAGC) de propriedade da Universidade Federal do Piauí, as quais foram cedidas na forma de sementes à Universidade Estadual de Maringá para fins de pesquisas. As populações foram formadas da seguinte maneira: Pop-1: C. annuum var glabriusculum (acessos: BAGC 11, BAGC 36, BAGC 59 e BAGC 67), Pop-2: C. chinense (acessos: BAGC 06, BAGC 07, BAGC 23 e BAGC 24), Pop-3: C. baccatum var. pendulum (acesso: BAGC 26).

Após a coleta das sementes, obtidas em frutos diferentes de aproximadamente vinte plantas, as mesmas foram secas naturalmente, identificadas e armazenadas por um período sob refrigeração. Pop-1 e Pop-2 foram representadas por quarenta e oito plantas cada; já a Pop-3 foi representada por vinte plantas, não havendo repetições. As amostras de sementes foram semeadas em bandejas de isopor, preenchidas com substrato comercial, sendo posto apenas uma semente por célula. Até esta etapa, as mudas foram mantidas em casa de vegetação e receberam água diariamente. Aos cinquenta dias após a semeadura as mudas foram transplantadas para vasos plásticos contendo terra comum e adubação orgânica.

Em cada vaso foram acondicionadas quatro plantas da mesma espécie, devidamente identificadas. Foram expostas ao ambiente natural e irrigadas quando necessário.

As amostras (folhas) de cada planta foram acondicionadas em tubos Eppendorf (1,5 mL) para a homogeneização. Foi utilizada uma solução de extração: Tampão Fosfato $1 \mathrm{M}$; pH 7,0, PVP-40 5\%, EDTA 1,0 mM, $\beta$-mercaptoetanol 0,5\%. Foi acrescentado $60 \mu \mathrm{L}$ de solução de extração em cada tubo e, com o auxílio de um bastão de vidro, as amostras foram maceradas sob gelo. Os tubos foram centrifugados a $12.000 \mathrm{rpm}$ durante 30 minutos a $4^{\circ} \mathrm{C}$.

Foi utilizada a técnica de eletroforese em gel de amido horizontal em um sistema contínuo. Obteve-se a análise de cinco sistemas isoenzimáticos, utilizando-se de dois tampões: tris citrato (TC), $\mathrm{pH} 7,0$ : tris $0,35 \mathrm{M}$, ácido cítrico 0,043 M; TEM, pH 7,4: tris 0,1 M, ácido 
maleico 0,1 M, EDTA 0,01 M, cloreto de magnésio $0,01 \mathrm{M}$, na cuba de eletroforese e os mesmos tampões foram diluídos 15 vezes para a preparação dos géis.

Preparou-se uma solução com amido de milho (penetrose 50), água destilada e uma solução tampão. A solução foi aquecida até o ponto de fervura e, logo após, vertida em uma placa de vidro previamente aquecida com bordas de 0,6 $\mathrm{cm}$. O gel foi resfriado por 24 horas para futura aplicação das amostras.

O extrato protéico (sobrenadante) separado pela centrifugação foi aplicado no gel com auxílio de pequenas tiras de papel-filtro (4 x $8 \mathrm{~mm}$ ) Whatman $3 \mathrm{MM}^{\circledR}$ embebidas com o sobrenadante. Em seguida, foi submetida à eletroforese sob refrigeração, durante 17 horas. A corrente elétrica medida nas extremidades dos géis foi de aproximadamente 30-40v, sendo 300v na fonte.

Após a corrida eletroforética, o gel foi cortado horizontalmente em fatias, as quais foram incubadas em soluções histoquímicas específicas e desejadas para cada sistema isoenzimático, seguindo protocolo de Murphy et al. (1996).

Posteriormente a um período de incubação do gel ao escuro, sob uma temperatura de $37^{\circ} \mathrm{C}$, aguardou-se a visualização das bandas nos géis, sendo estes colocados em uma solução conservante: metanol/água/ácido acético (5:5:1) por 24 horas e, em seguida, fotografados e analisados.

Os cinco sistemas isoenzimáticos analisados em gel de amido foram: GPI (5.3.1.9), IDH (1.1.1.14), ACP (3.1.3.2), MDH (1.1.1.37) e PGM (5.4.2.2). A nomenclatura das enzimas utilizadas foi proposta por Murphy et al. (1996). A interpretação genética foi baseada na estrutura quaternária das enzimas segundo Ward et al. (1992). As estimativas foram obtidas com o auxílio do programa Pop gene 3.1 (Yeh et al., 1997), tais como variabilidade genética estimada pelo cálculo da heterozigosidade $\left(\mathrm{H}_{\mathrm{e}}\right.$ e $\left.\mathrm{H}_{\mathrm{o}}\right)$, de acordo com Nei (1978), parâmetros estatísticos de fixação $\left(\mathrm{F}_{\mathrm{IS}}, \mathrm{F}_{\mathrm{IT}}\right.$ e $\left.\mathrm{F}_{\mathrm{ST}}\right)$, de Wright (1978), frequências alélicas, identidade (I) e distância genética (D), de Nei (1972). A partir da identidade e da distância genética, foi construído um dendrograma [(método de agrupamento pelo algoritmo UPGMA (Unweighted Pair Group With Arithmetic Means)] das populações estudadas.

\section{RESULTADOS E DISCUSSÃO}

A expressão enzimática dos alelos detectados neste estudo está ilustrada nos zimogramas representados pela Figura 1. Observa-se que o alelo $a$ para os loci Mdh-1, Mdh-2 e Gpi e o alelo b para os loci Gpi e Idh foram os únicos que estiveram presentes em todas as populações. Ainda, nesta figura, é possível observar que apenas o sistema isoenzimático $\mathrm{MDH}$ revelou todos os alelos para todas as populações. Visualiza-se também que a enzima GPI foi a que apresentou um maior número de alelos por locus (três alelos), enquanto a enzima MDH apresentou um menor número de alelos por locus (1 alelo para cada locus).

Das análises eletroforéticas obtidas, foi possível identificar sete loci e 13 alelos, dentre os cinco sistemas isoenzimáticos estudados nas três populações de Capsicum. Destes 13 alelos detectados, observou-se que a Pop-1 ( $C$. annuum var. glabriusculum), comparada às demais populações, foi a única que apresentou o alelo $G p i(c)$, o alelo $\operatorname{Idh}(a)$ e o alelo $A c p(b)$. O alelo Pgm-1(b) e Pgm-2(b) só foi detectado na Pop-3 (C. baccatum var. pendulum) em relação às demais populações analisadas (Tabela 1). Este é um aspecto interessante para o material biológico depositado no banco de germoplasma, pois os alelos exclusivos podem ser utilizados como marcadores dos acessos dentro do banco. A diversidade genética alta é um aspecto importante para a conservação de bancos de germoplasma, mas encontrar alelos exclusivos também tem importância prática na identificação do genótipo, para monitorar a estabilidade fenotípica por ocasião do uso destas amostras para o cultivo e produção de mudas e também para o melhoramento da espécie.

Apenas dois loci para a enzima $\mathrm{MDH}$ é incomum, pois pelo menos três loci podem ser descritos em diversas espécies de plantas: um locus para MDH mitocondrial, um para MDH citosólica e um para MDH peroxissomal (Taiz \& Zeiger, 2004). Detectar menos loci que três deve estar relacionado com a menor eficiência da extração das enzimas do material biológico. Logo, o tampão

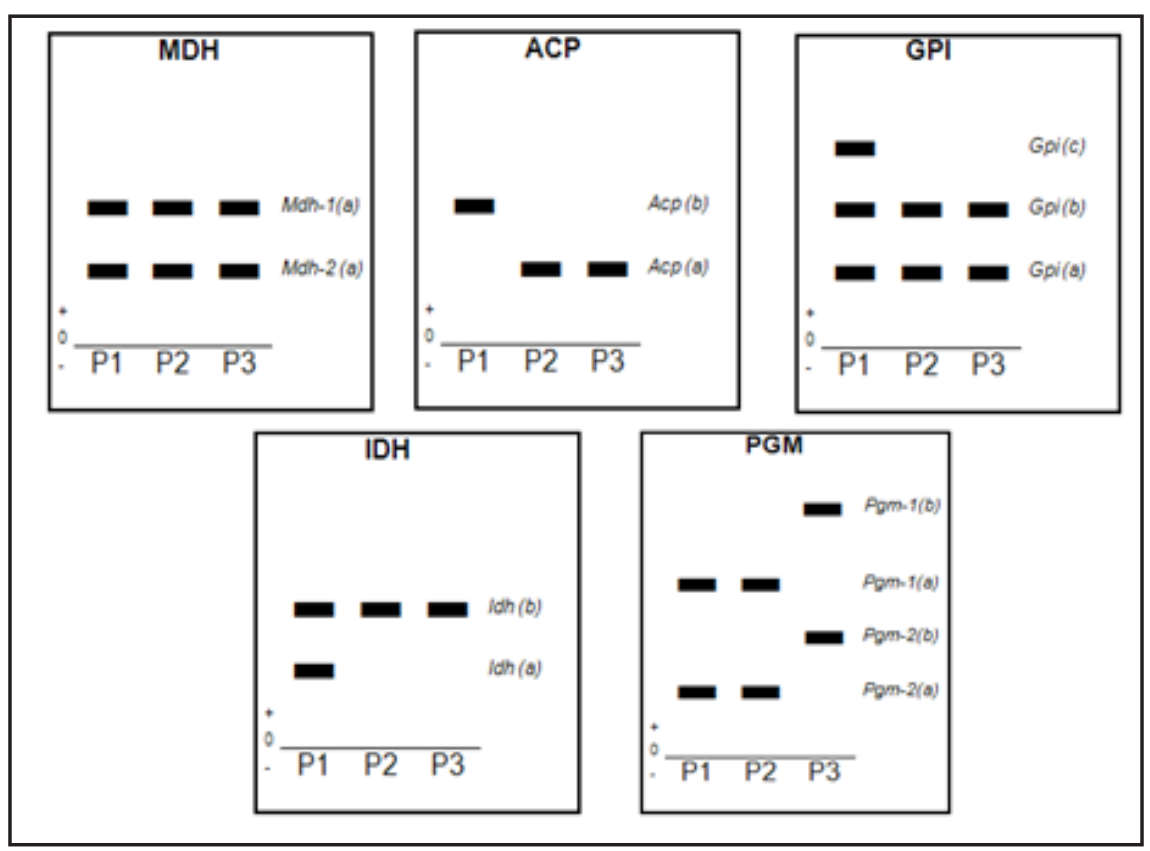

Figura 1. Zimograma dos cinco sistemas enzimáticos analisados em gel de amido, com seus respectivos alelos, presentes nas populações (P1: C. annuum var. glabriusculum; P2: $C$. chinense; P3: C. baccatum var. pendulum) [zymogram of five enzymatic systems in starch gel electrophoresis with their loci and alleles detected in the analyzed populations (P1: C. annuum var. glabriusculum; P2: C. chinense; P3: C. baccatum var. pendulum)]. Maringá, UEM, 2011. 


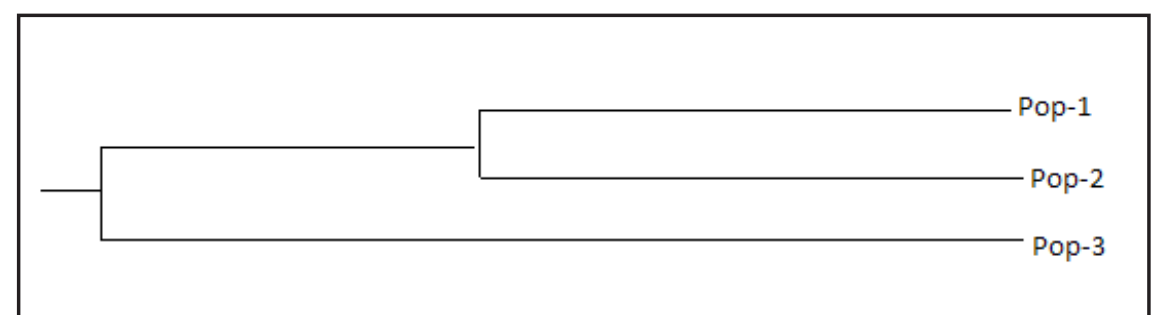

Figura 2. Dendrograma de UPGMA calculado a partir da distância genética de Nei (1978) entre as três populações de Capsicum (Pop-1: C. annuum var. glabriusculum; Pop-2: $C$. chinense; Pop-3: C. baccatum var. pendulum). [UPGMA dendrogram constructed from genetic distance of Nei (1978) among three populations of Capsicum (Pop-1: C. annuum var. glabriusculum; Pop-2: C. chinense; Pop-3: C. baccatum var. pendulum)]. Maringá, UEM, 2011.

Tabela 1. Estimativas de freqüências alélicas das populações de Capsicum (Pop-1: C. annuum var. glabriusculum; Pop-2: C. chinense; Pop-3: C. baccatum var. pendulum); $\mathrm{N}^{\circ}$ : número de indivíduos analisados [estimates of allele frequencies in three populations of Capsicum) (N: number of analyzed individuals) (Pop-1: C. annuum var. glabriusculum; Pop-2: C. chinense; Pop-3: C. baccatum var. pendulum)]. Maringá, UEM, 2011.

\begin{tabular}{|c|c|c|c|c|}
\hline Locus & Alelo & Pop-1 & Pop-2 & Pop-3 \\
\hline \multirow{3}{*}{ Gpi } & A & 0,9574 & 0,9787 & 0,9000 \\
\hline & B & 0,0213 & 0,0213 & 0,1000 \\
\hline & $\mathrm{C}$ & 0,0213 & - & - \\
\hline \multirow{2}{*}{$I d h$} & A & 0,9512 & - & - \\
\hline & B & 0,0488 & 1,0000 & 1,0000 \\
\hline \multirow{2}{*}{$A c p$} & A & - & 1,0000 & 1,0000 \\
\hline & $\mathrm{B}$ & 1,0000 & -....... & - \\
\hline$M d h-1$ & A & 1,0000 & 1,0000 & 1,0000 \\
\hline$M d h-2$ & A & 1,0000 & 1,0000 & 1,0000 \\
\hline \multirow{2}{*}{ Pgm-1 } & A & 1,0000 & 1,0000 & - \\
\hline & B & - & - & 1,0000 \\
\hline \multirow{2}{*}{ Pgm-2 } & A & 1,0000 & 1,0000 & - \\
\hline & B & - & - & 1,0000 \\
\hline $\mathrm{N}^{\mathrm{o}}$ & & 48 & 48 & 20 \\
\hline
\end{tabular}

utilizado para homogeneizar e extrair as proteínas é um fator crítico para proteger as enzimas e permitir a sua identificação no gel.

Objetivando a padronização das condições eletroforéticas das isoenzimas malato desidrogenase (MDH) e fosfatase ácida (ACP) em Conyza canadensis e Conyza bonariensis, Bassi et al. (2010) testaram quatro soluções de extração para solubilizar as folhas de Conyza sp., sendo uma delas a mesma solução utilizada neste trabalho (0,05 g PVP-40, 10 $\mu \mathrm{L}$ EDTA $1 \mathrm{mM}, 5 \mu \mathrm{L} \beta$-mercaptoetanol e $1 \mathrm{~mL}$ tampão fosfato $1 \mathrm{M}, \mathrm{pH} 7,0) \mathrm{e}$ duas soluções tampão, uma contendo tampão tris $(0,0103 \mathrm{M})$ e ácido cítrico $(0,0028 \mathrm{M}) \mathrm{pH} 7,0$ e a outra tampão tris trabalhando com isoenzimas de tecidos de Cereus peruvianus, com o objetivo de testar sete tipos de soluções de extração para as enzimas ADH, MDH, IDH, SDH, ACP, EST e PER, concluíram que as devidas soluções resultaram na mesma intensidade e coloração de bandas nos géis. Porém, algumas pequenas diferenças puderam ser observadas, como é o caso da isoenzima $\mathrm{MDH}$, a qual apresentou um locus a mais em uma devida solução testada. Logo, prova-se que a escolha e a padronização de uma solução de extração é um fator crítico e limitante nos trabalhos que envolvam a utilização de isoenzimas.

$\mathrm{Na}$ Tabela 1 podem ser evidenciadas as frequências alélicas de cada locus em cada população. Os loci estão em equilíbrio de Hardy-Weinberg. De acordo com a observação das frequências alélicas, foi possível ainda identificar cinco alelos exclusivos. Três destes alelos foram encontrados na Pop-1 ( $C$. annuum var. glabriusculum) Gpi-(c), $I d h$-(a) e $A c p$-(b) com frequências de 0,0213, 0,9512 e 1,0000, respectivamente, enquanto a Pop-3 (C. baccatum var. pendulum) apresentou o alelo Pgm-1-(b) e Pgm-2-(b), com freqüências de $100 \%$ em ambos.

Os trabalhos de Hernández-Verdugo et al. (2001) em C. annuum, ao proporem padrões para nove enzimas (GOT, APX, ME, PGI, IDH, MDH, 6-PGD, ACPH, MNR), revelaram doze loci polimórficos e um total de 35 alelos. $\mathrm{O}$ locus Idh-2 apresentou cinco alelos, as frequências alélicas variaram de acordo com cada alelo [alelo $1(0-0,500)$, alelo 2 (0-0,846), alelo $3(0-0,526)$, alelo 4 $(0-0,844)$ e o alelo $5(0-0,855)]$; o locus $M d h-2$ apresentou três alelos, com as respectivas frequências [alelo $1(0,058$ $0,194)$, alelo $2(0,523-0,808)$ e o alelo 3 ( 0,135-0,392)] e o locus Mdh-4 apresentou também três alelos com as seguintes frequências [alelo $1(0-0,436)$, alelo 2 $(0,462-0,917)$ e o alelo $3(0-0,250)]$.

As estimativas das freqüências alélicas foram utilizadas em um teste de qui quadrado de homogeneidade para demonstrar a diferenciação entre as populações (Tabela 1). Neste estudo, dos sete loci analisados, quatro (Idh, Acp, Pgm-1 e Pgm-2) apresentaram frequências alélicas diferentes $(\mathrm{p}<0,05)$ 
Tabela 2. Heterozigosidade esperada e observada $\left(\mathrm{H}_{\mathrm{e}}\right.$ e $\left.\mathrm{H}_{\mathrm{o}}\right)$; percentagem de loci polimórficos (P) e número de alelos por locus (K) (Pop-1: C. annuum var. glabriusculum; Pop-2: $C$. chinense; Pop-3: C. baccatum var. pendulum); Entre parênteses está o desvio padrão de $\mathrm{H}_{\mathrm{e}}$ e $\mathrm{K}$ [expected and observed heterozygosity $\left(\mathrm{H}_{\mathrm{e}}\right.$ and $\left.\mathrm{H}_{\mathrm{o}}\right)$; proportion of polymorphic loci (P); number of allele per locus $(\mathrm{K})$; Between parentheses are shown the $\mathrm{H}_{\mathrm{e}}$ and $\mathrm{K}$ standard deviation) (Pop-1: C. annuum var. glabriusculum; Pop-2: C. chinense; Pop-3: C. baccatum var. pendulum)]. Maringá, UEM, 2011.

\begin{tabular}{lcccc}
\hline Populações & $\mathbf{H}_{\mathbf{e}}$ & $\mathbf{H}_{\mathbf{0}}$ & $\mathbf{P}(\%)$ & $\mathbf{K}$ \\
\hline Pop-1 & $0,0253(0,4333)$ & 0 & 28,57 & $1,4286(0,7868)$ \\
Pop-2 & $0,0060(0,0159)$ & 0 & 14,29 & $1,1429(0,3780)$ \\
Pop-3 & $0,0264(0,0698)$ & 0 & 14,29 & $1,1429(0,3780)$ \\
\hline
\end{tabular}

Tabela 3. Estatísticas F de Sewall Wright para cada locus das três populações de Capsicum analisadas (F statistics of Sewall Wright for each locus of three Capsicum populations analysed). Maringá, UEM, 2011.

\begin{tabular}{lcccc}
\hline Locus & $\mathbf{N}$ & $\mathbf{F}_{\text {IS }}$ & $\mathbf{F}_{\text {IT }}$ & $\mathbf{F}_{\text {ST }}$ \\
\hline$G p i$ & 114 & 1,0000 & 1,0000 & 0,0249 \\
$I d h$ & 103 & 1,0000 & 1,0000 & 0,9286 \\
Acp & 111 & $* * * *$ & 1,0000 & 1,0000 \\
$M d h-1$ & 109 & $* * * *$ & $* * * *$ & 0,0000 \\
$M d h-2$ & 110 & $* * * *$ & $* * * *$ & 0,0000 \\
Pgm-1 & 114 & $* * * *$ & 1,0000 & 1,0000 \\
Pgm-2 & 114 & $* * * *$ & 1,0000 & 1,0000 \\
\hline Média & 110,5 & 1,0000 & 1,0000 & 0,9284 \\
\hline
\end{tabular}

Tabela 4. Valores de identidade genética (acima da diagonal) e distância genética (abaixo da diagonal) de Nei (1972), entre as três populações de Capsicum (Pop-1: C. annuum var. glabriusculum; Pop-2: C. chinense; Pop-3: C. baccatum var. pendulum) [values of genetic identity (above diagonal) and genetic distance (below diagonal) of Nei (1972) among the three populations of Capsicum (Pop-1: C. annuum var. glabriusculum; Pop-2: C. chinense; Pop-3: C. baccatum var. pendulum)]. Maringá, UEM, 2011.

\begin{tabular}{llll}
\hline Pop & Pop-1 & Pop-2 & Pop-3 \\
\hline Pop-1 & $* * * * *$ & 0,7236 & 0,4269 \\
Pop-2 & 0,3236 & $* * * * *$ & 0,7088 \\
Pop-3 & 0,8512 & 0,3441 & $* * * * *$ \\
\hline
\end{tabular}

e apenas três (Gpi, Mdh-1 e Mdh-2) apresentaram frequências alélicas semelhantes $(p>0,05)$. Sendo assim, a maior proporção de loci com frequências alélicas diferentes $(p<0,05)$ pode indicar que a diversidade genética deve ser maior entre as populações do que dentro das mesmas.

Vidigal et al. (2009), trabalhando com $C$. annuum, objetivando acompanhar o desenvolvimento fisiológico durante a maturação de sementes por meio de análises enzimáticas, obtiveram apenas um locus para as enzimas malato desidrogenase (MDH), álcool desidro- presente estudo que as três populações analisadas demonstraram possuírem loci polimórficos, destacando-se a Pop-1 (C. annuum var. glabriusculum) com $28,57 \%$, sendo esta a maior percentagem. Quanto ao número médio de alelos por locus verificou-se uma variação de 1 a 1,4286, sendo o maior número de alelos encontrados na Pop-1 (C. annuum var. glabriusculum. Sob uma visão geral, é possível concluir que a heterozigosidade observada $\left(\mathrm{H}_{\mathrm{o}}\right)$ foi 0 (zero) para todas as populações devido a todos os indivíduos da amostra serem homozigotos. O predomínio de fenótipos homozigotos observado nas amostras de pimentas analisadas é esperado em razão da autocompatibilidade descrita para estas espécies (Casali \& Couto, 1984). A autofecundação tem sido descrita como regra no gênero Capsicum (Onus $\&$ Pickersgill, 2004). A heterozigosidade esperada $\left(\mathrm{H}_{\mathrm{e}}\right)$ também foi baixa quando comparada a outras espécies de plantas (Tabela 2).

Os dados de parâmetros populacionais $\mathrm{F}_{\mathrm{IS}}$ e $\mathrm{F}_{\mathrm{IT}}$ (estatística de Wright) apresentados na Tabela 3 mostram que há um excesso muito grande de homozigotos em todas as populações analisadas neste estudo, enquanto os valores de $\mathrm{F}_{\mathrm{ST}}$ mostram que as três populações são diferentes geneticamente.

A polinização cruzada tem sido sugerida em função da heterogeneidade alta observada em plantas de $C$. annuum e $C$. chinense na análise de loci para isoenzimas alfa e beta esterases (resultados ainda não publicados). As isoenzimas esterases também têm sido descritas como o sistema enzimático mais polimórfico em espécies de Capsicum (Barrera et al., 2005). Mas, considerando os sistemas enzimáticos investigados neste estudo (ACP, GPI, IDH, MDH e PGM), o padrão homozigoto é prodominante.

A identidade genética (I) indica a proporção dos produtos dos genes, que não são diferenciados por procedimentos eletroforéticos (Dobzhansky et al., 1977) e seu valor varia de 0 a 1 . Thorpe \& Solé-Cava (1994) concluíram que $85 \%$ dos valores da identidade genética entre espécies do mesmo gênero excedem 0,35 e $97 \%$ dos valores estão abaixo de 0,85 . Entre espécies de gêneros di- 
ferentes, este valor em $77 \%$ dos casos, é menor que 0,35 , enquanto para populações da mesma espécie $98 \%$ excede 0,85 . Os valores de identidade genética e distância genética colhidos neste experimento estão descritos na Tabela 4 . Os valores da Tabela 4 confirmam o status taxonômico de espécies diferentes das três populações analisadas.

O dendrograma ilustrado na Figura 2 aponta a formação de dois grupos: Pop-1+Pop-2 (C. annuum var. glabriusculum $+C$. chinense) $\mathrm{e}$ Pop-3 (C. baccatum var. pendulum), o que comprova o proposto por Pickersgill (1997) ao afirmar que o gênero Capsicum pode ser dividido em três grandes Complexos, de acordo com um possível cruzamento entre as espécies: Complexo annuum, Complexo baccatum e Complexo pubescens. O Complexo annuum é representado pelas espécies: C. annuum (variedades annuum e glabriusculum), C. frutescens, C. chacoense, C. galapagoensei e $C$. chinense. As espécies $C$. baccatum (variedades baccatum, pendulum e pratermissum) e C. tovari representam o Complexo baccatum. O Complexo pubescens compreende as espécies $C$. cardenasi, C. eximium e C. pubescens.

Os dados apresentados no presente estudo mostram que as espécies de Capsicum analisadas apresentam baixa variabilidade genética e que são geneticamente diferentes entre si.

\section{AGRADECIMENTOS}

À UFPI pelo material biológico utilizado no trabalho e à CAPES pelo auxílio financeiro para o mesmo.

\section{REFERÊNCIAS}

BARBOSA RI; LUIZ FJF; NASCIMENTO FILHO HR; MADURO CB. 2002. Pimentas do gênero Capsicum cultivadas em Roraima, Amazônia brasileira: Espécies domesticadas. Acta Amazônica 32: 177-192.

BARRERA LQ; GARCIA MC; GIRALDO MC; MELGAREJO LM. 2005. Caracterización por isoenzimas de accesiones de Capsicum pertencientes a La colección Amazonica Colombiana. Revista Colombiana de Biotecnologia 2: 59-65.
BASSID; MANGOLIN CA; OLIVEIRAJUNIOR RS; MACHADO MFPS; FREGONEZI AMDT; OLIVEIRA-COLLET SA. 2010. Padronização das condições eletroforéticas das isoenzimas Malato Desidrogenase e Fosfatase Ácida de Conyza canadensis (L.) e Conyza bonariensis (L.). In: CONGRESSO BRASILEIRO DA CIÊNCIA DAS PLANTAS DANINHAS, 27. Resumos Expandidos.. Ribeirão Preto: p. 436-440.

BENTO CS; SUDRE CP; RODRIGUES R; RIVA EM; PEREIRA MG. 2007. Descritores qualitativos e multicategóricos na estimativa da variabilidade fenotípica entre acessos de pimentas. Scientia Agraria 8: 149-156.

CARVALHO SIC; BIANCHETTI LB; BUSTAMANTE PG; SILVA DB. 2003. Catálogo de germoplasma de pimentas e pimentões (Capsicum spp.) da Embrapa Hortaliças. Brasília: Embrapa Hortaliças. 49p.

CASALI VW; COUTO FAA. 1984. Origem e botânica de Capsicum. Informe Agropecuário 10: 8-10.

COSTA FR; PEREIRA TNS; VITÓRIA AP; CAMPOS KP; RODRIGUES R; SILVA DH; PEREIRA MG. 2006. Genetic diversity among Capsicum accessions using RAPD markers. Crop Breeding and Applied Biotechnology 6: 18-23.

CRUZ CD; CARNEIRO PCS. 2003. Modelos biométricos aplicados ao melhoramento genético. Viçosa: UFV. 585p.

DOBZHANSKY T; AYALA FJ; STEBBINS GL; VALENTINE JW. 1977. Evolution. San Francisco: WH Freeman and Company. 572p.

HERNÁNDEZ-VERDUGO S; LUNA-REYES R; OYAMA K. 2001. Genetic structure and differentiation of wild and domesticated populations of Capsicum annuum (Solanaceae) from Mexico. Plant System Evolution 226: 129-142.

LEFEBVRE V; GOFFINET B; CHAUVET JC; CAROMEL B; SIGNORET P; BRAND R; PALLOIX A. 2001 Evaluation of genetic distances between pepper inbred lines for cultivar protection purposes: comparison of AFLP, RAPD and phenotypic data. Theoretical and Applied Genetics 102: 741-750.

LOAIZA-FIGUEROA F; RITLAND K; CANCINO JAL; TANKSLEY SD. 1989. Patterns of genetic variation of the genus Capsicum (Solanaceae) in Mexico. Plant Systematics and Evolution 165: 159-188.

MACHADO MFPS; PRIOLI AJ; MANGOLIN CA. 1993. Malate dehydrogenase (MDH; EC 1.1.1.37) isozymes in tissues and callus cutures of Cereus peruvianus (Cactaceae). Biochemical Genetics 31: 569-575.

MANGOLIN CA; MACHADO MFPS. 1997. Isozyme extraction from shoot tissue of Cereus peruvianus (Cacataceae) for electrophoretic analysis. Biochemical Genetics 35: 205-210.

MOREIRA GR; CALIMAN FRB; SILVA DJH; RIBEIRO CSC. 2006. Espécies e variedades de pimenta. Informe Agropecuário 27: 16-29.

MURPHY RW; SITES JUNIOR JW; BUTH DG; HAUFLER CH. 1996. Proteins: isozyme electrophoresis. In: HILLS DM; MORITZ
C; MABLE BK (eds). Molecular systematic. Massachusetts: Sinauer Associates. p. 51-120.

NEI M. 1978. Estimation of average of heterozygosity and genetic distance from small number of individuals. Genetics 89: 583-590.

NEI M. 1972. Genetic distance between populations. American Naturalist 106: 238292.

ONUS AN; PICKERSGILL B. 2004. Unilateral incompatibility in Capsicum (Solanaceae) occurrence and taxonomic distribution. Annual Botany 94: 289-295.

PICKERSGILL B. 1997. Genetic resources and breeding of Capsicum spp. Euphytica 96: 129-133.

RÊGO ER. 2001. Diversidade, herança e capacidade de análise combinatória em pimenta (Capsicum baccatum). Viçosa: UFV. $118 \mathrm{p}$. (Tese doutorado).

REIFSCHNEIDER FJB. 2000. Capsicum: pimentas e pimentões no Brasil. Brasília: EMBRAPA. 113p.

RIBEIRO CSC; SOUZA OB; LOPES D; REIFSCHNEIDER FJB. 2003. Programa de melhoramento genético de Capsicum da EMBRAPA Hortaliças para processamento industrial. In: CONGRESSO BRASILEIRO DE MELHORAMENTO DE PLANTAS, 2. Trabalhos Técnicos... Porto Seguro: SBMP, 2003.

RUFINO JLS; PENTEADO DCS. 2006. Importância econômica, perspectivas e potencialidades do mercado para pimenta. Informe Agropecuário 27: 7-15.

SUDRÉ CP; RODRIGUES R; RIVA EM; KARASAWA M; AMARAL JÚNIOR AT. 2005. Divergência genética entre acessos de pimentas e pimentões utilizando técnicas multivariadas. Horticultura Brasileira 23: 22-27.

TAIZ L; ZEIGER R. 2004. Fisiologia vegetal. Califórnia: Cummings. 719p.

THORPE JO; SOLÉ-CAVA AM. 1994. The use of allozyme electrophoresis in invertebrate systematic. Zoologica Scripta 23: 3-18.

TOQUICA SP; RODRÍGUEZ F; MARTÍNEZ E; DUQUE MC; TOHME J. 2003. Molecular characterization by AFLPs of Capsicum germplasm from the Amazon Department in Colombia. Genetic Resources and Crop Evolution 50: 639-647.

VIDIGAL DS; DIAS DCFS; PINHO EVR; DIAS LAS. 2009. Alterações fisiológicas e enzimáticas durante a maturação de sementes de pimenta (Capsicum annuum L.). Revista Brasileira de Sementes 31: 129-136.

WARD RD; SKIBINSKI DOF; WOODWARK M. 1992. Protein heterozygosity, protein structure, and taxonomic differentiation. Evolutionary Biology 26: 73-159.

WRIGHT S. 1978. Evolution and genetics of populations. Chicago: The University of Chicago Press. 465p.

YEH FC; YANG RC, BOYLE TBJ; YE ZH; MAO JX. 2011, 20 julho. POPGENE, the user-friendly shareware for population genetic analysis. [1997]. Disponível em: http://www. ualberta.ca/ fyeh/faq.htm. 